\title{
Diagnóstico espaço-temporal das áreas impactadas pela MPL - Mineração Pedra Lavrada (Santa Luzia-PB), na extração de vermiculita
}

\section{Amanda Carolina Almeida Bezerra Alencar ${ }^{1}$, Thâmara Pessoa Goes da Costa*', Clayriston Sousa Alves', Franklin Mendonça Linhares ${ }^{2}$}

${ }^{1}$ Faculdade Internacional da Paraíba. Av. Monsenhor Walfredo Leal, 512 - Centro, João Pessoa PB (CEP 58020-540).*E-mail: thamarapessoa2@hotmail.com.

${ }^{2}$ Universidade Federal da Paraíba, Centro de Ciências Exatas e da Natureza, Programa de PósGraduação em Geografia, João Pessoa - PB (CEP 58051-900).

Resumo. A mineração é um dos setores básicos da economia, contribuindo de forma decisiva para o desenvolvimento do país, desde que seja operada com responsabilidade social e ambiental. O presente estudo tem como objetivo diagnosticar o espaço-temporal da área degradada pela extração de vermiculita, e propor adequar a atividade no Plano de Recuperação de Área Degrada (PRAD) apresentado pela empresa. O trabalho foi desenvolvido com o apoio da Empresa MPL - Mineração Pedra Lavrada Ltda, localizada no Município de Santa Luzia-PB, na Região do Seridó Ocidental Paraibano, e com os resultados sido coletados em outubro de 2014. Para a realização do estudo avaliou-se a área nos seguintes aspectos: a época em que a área foi impactada e o tipo de impacto causado. Após estes estudos, foi feita a quantificação da área alterada pela atividade minerária, para posteriormente propor a recomposição do passivo gerado, utilizando as técnicas de geoprocessamento e sensoriamento remoto para chegar aos resultados finais.

Palavras-chave: Mineração, Vermiculita, Rejeito, Geoprocessamento.

Abstract. Space-time diagnosis of impacted areas by MPL Mineração Pedra Lavrada, in the extraction of the vermiculite. Mining is one of the basic sectors of the economy, contributing decisively to the development of the country as long as it is operated with social and environmental responsibility. The present study aims to diagnose space-temporal degraded areas from the mining of vermiculite and proposes the adaptation of the activity into the Recovery Plan of Degraded Area (PRAD) presented by the company. The work was developed with the support of the Company MPL Mineração Pedra Lavrada Ltda, located in the City of Santa Luzia-PB in the Western Seridó of Paraíba Region. The results were collected in October 2014. For the realization of the studies we evaluated the area in the following aspects: the time when the area was impacted and what type of impact was caused. After these studies, the quantification of the affected areas was made for afterwards propose the restoration of the environmental liabilities generated during the process of mining, using the techniques of GIS and remote sensing to get to the final results.

Keywords: Mining, Vermiculite, Waste, GIS.
Recebido: 29/12/2014

Aceito: 23/04/2015

Publicado: 30/06/2015

Acesso Aberto Artigo completo

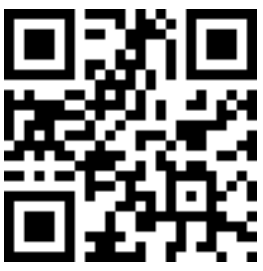




\section{Introdução}

As atividades humanas, principalmente as de ordem econômica, alteram substancialmente o meio ambiente. Através destas, o homem extrai recursos naturais que alimentam toda a economia mundial. Sem elas, nenhuma das atividades subsequentes pode existir. A mineração e a agricultura, junto com a exploração florestal, a produção de energia, os transportes, as construções civis (urbanização, estradas, etc.) e as indústrias básicas (químicas e metalúrgicas) são os causadores de quase todo o impacto ambiental existente na terra. O impacto das demais atividades econômicas torna-se pouco significativo quando comparado às citadas anteriormente (Silva, 2007).

A mineração, evidentemente, causa um impacto ambiental considerável. Ela altera intensamente a área minerada e as áreas vizinhas, onde são feitos os depósitos de estéril e de rejeito. Além do mais, quando temos a presença de substâncias químicas nocivas na fase de beneficiamento do minério, isto pode significar um problema sério do ponto de vista ambiental (Kageiama et al., 2003).

Ao longo dos séculos, as atividades antrópicas vêm causando uma grande degradação ao meio ambiente. Diante disso, o mundo passa por vários problemas ambientais (Kageiama et al., 2003).

Um desses problemas é o abandono da área minerada, que tem por consequência o fechamento da mina, uma etapa certa de suceder, seja por exaustão da jazida, seja por questões de viabilidade econômica (Taveira, 2003).

Historicamente no Brasil, as minas exauridas eram abandonadas sem que fossem tomadas providências para reduzir os riscos e impactos socioambientais. Só a partir da década de 1980, através da Constituição Federal, sentiu-se a necessidade de criar lei e decretos que tratem de áreas mineradas, como o artigo 225, § $2^{\circ}$, da Constituição Federal, onde prever que as empresas de mineração são responsáveis pelo encerramento da mina e pela reabilitação das áreas mineradas. Erigido também pelo art. 19, da Lei $n^{\circ}$ 7.805/1989, com o mesmo enfoque da Lei $\mathrm{n}^{\circ}$ 6.938/1981, isto é, a responsabilidade civil objetiva ou sem culpa.

No entanto, ainda se veem empreendedores abandonando áreas mineradas ou implantando medidas ineficazes e insatisfatórias para o adequado encerramento de mina, por não terem recursos financeiros suficientes, uma vez que na fase de fechamento não há mais geração de receita e geralmente não se faz, durante a operação do empreendimento, uma provisão de recursos (Foschini et al., 2009).

Segundo Portaria DNPM $\mathrm{n}^{\circ}$ 237/2001 - NRM no 20, no Brasil existe a exigência da apresentação de um Plano de Recuperação de Áreas Degradadas - PRAD ao órgão ambiental competente, durante o processo de licenciamento ambiental, para todos os empreendimentos de mineração, além de Plano de Fechamento ou de Suspensão da Mina.

O plano de fechamento de mina tem como principal objetivo a redução dos riscos ambientais e a diminuição da geração de resíduos e efluentes, além da promoção da recuperação de áreas degradadas, e de garantir que a comunidade local não sofra queda na qualidade de vida, seja pelo desenvolvimento da mineração como pelo seu fechamento (Warhurst e Noronha, 1999).

O art. $3^{\circ}$, do Decreto $n^{\circ}$ 97.632/1989 (Brasil, 1989), estabelece que a recuperação deverá ter por objetivo o retorno do sítio degradado a uma forma de utilização de acordo com um plano preestabelecido para uso do solo, visando à obtenção de uma estabilidade do meio ambiente.

Para Gripp e Nonato (1993) a recuperação constitui o processo de reverter as terras degradadas pela mineração em terras produtivas e auto-sustentáveis.

Isso implica dizer que área a ser recuperada deve estar apta para algum uso produtivo em condições de equilíbrio químico, físico e biológico.

Uma forma de corrigir os passivos gerados pelas cavas de minas a céu aberto é preenchê-las com o estéril de cavas em abertura ou até mesmo com o rejeito do beneficiamento gerado e, posteriormente, revegetá-las com espécies adequadas mediante o ambiente. Esse procedimento 
apresenta um benefício ambiental elevado, tendo em vista que além de recuperar a área minerada, evita também o passivo gerado pelo rejeito do beneficiamento.

Na região semiárida da Paraíba uma das atividades de maior expressão econômica é a mineração, gerando renda para população local e recursos para o estado, tendo por contra partida a geração de passivos ambientais, que se torna um ato comum entre as mineradoras, durante a lavra produzir rejeitos biologicamente inativos, que são acumulados nos pátios, e lugares impróprios como as margens das rodovias e estradas vicinais, entre outros. Isso acontece frequentemente devido à desvantagem econômica no reaproveitamento do rejeito da matéria prima, e também aos custos adicionais com o seu transporte, gerando assim, sobre a responsabilidade da mineradora, passivos ambientais a serem recuperados (Embrapa, 2008).

Outro problema é a forma de extração do minério, que é feita com a remoção da camada superficial do solo e que durante o processo de extração, altera a paisagem, resultando em crateras que deformam o solo-paisagem, tornando-se um grande problema para o meio ambiente, para os empreendimentos, e para a sociedade, ficando sob a responsabilidade da mineradora, a função de evitá-los e mesmo depois de gerados revertê-los.

Como forma de contribuir na avaliação dos problemas ambientais advindos da atividade de mineração, notadamente na extração da vermiculita, um mineral do grupo das micas que se constitui em um silicato hidratado de magnésio, ferro e alumínio, bastante utilizado no setor agrícola, na construção civil e em outras aplicações industriais, propõem-se através deste trabalho uma análise das ações adotadas pela empresa MPL - Mineração Pedra Lavrada no tocante à destinação dos rejeitos de sua mineração e da área degradada pela extração do minério.

\section{Metodologia}

\section{Caracterização da área de estudo}

A presente pesquisa é de caráter exploratório, conduzida metodologica- mente, a partir de estudos de campo e registros icnográficos.

Tais atividades foram realizadas na MPL - Mineração Pedra Lavrada Ltda, localizadas na margem da BR 230, km 277, no Município de Santa Luzia-PB. Como visto no mapa de localização (Figura 1).

O Município de Santa Luzia-PB encontra-se localizado na Região do Seridó Ocidental Paraibano e integrante da Região Metropolitana de Patos. Sua população é de 14.729 habitantes e sua área territorial de $442 \mathrm{~km}^{2}$ (IBGE, 2010). Está inserido no Polígono das Secas. Possui clima BshTropical, quente seco, semiárido com chuvas de verão. Segundo a divisão do Estado da Paraíba em regiões bioclimáticas, o município de Santa Luzia enquadra-se no clima 2b-Sub-desértico. A vegetação é do tipo Caatinga, com exceção de áreas localizadas ao sul de Santa Luzia com clima de Matas-Serranas. Esta área possui cotas mais elevadas com relevo suave-ondulado caracterizado por uma superfície de relevo bastante monótono e tratam-se das Serras Riacho do Fogo, Borborema e do Pinga. Elevações residuais, cristas e/ou outeiros pontuam a linha do horizonte. Esses relevos isolados testemunham os ciclos intensos de erosão que atingiram grande parte do sertão nordestino (CPRM, 2005).

A cidade é cercada por três açudes, por isso também é conhecida como "Cidade Ilha”, fazendo parte do domínio da SubBacia dos Rios Barra e Saco, os quais deságuam no Açude Público de Santa Luzia, constituindo as nascentes do Rio Quipauá, intermitente e de significativa importância socioeconômica para o município nas épocas chuvosas. Está incluído na área geográfica de abrangência do semiárido brasileiro, caracterizando-se por apresentar grande irregularidade no seu regime pluviométrico, que depende das massas de ar que vêm do litoral e do Oeste. Sua localização sobre a depressão do Rio Piranhas e a presença nas imediações, da Serra da Borborema, constituem as principais barreiras físicas para a existência de um clima mais ameno e para regularização do regime das chuvas definida pelo Ministério da Integração Nacional, em 2005. Esta delimitação tem como critérios o índice pluviométrico, o índice de aridez e o risco de seca. 


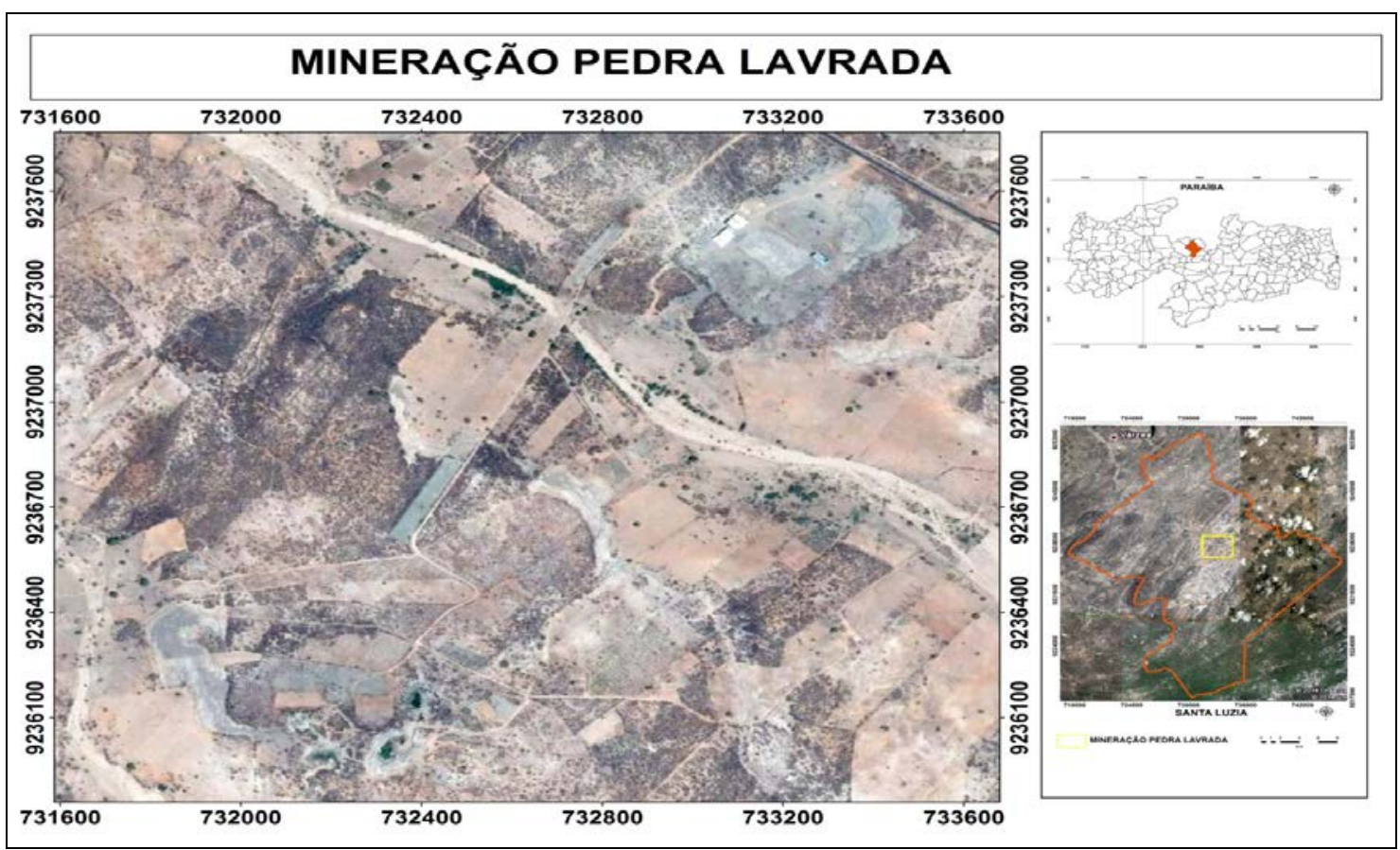

Figura 1. Mapa de Localização.

\section{Materiais e métodos}

A pesquisa realizada foi do tipo empírica e explicativa, com a utilização de trabalho de campo e descrições dos impactos ambientais da área de estudo, causados pela ação mineradora. O método de pesquisa aplicado é o método indutivo, que consiste em estudar as partes para compreender o todo, em que foram analisados os aspectos naturais da área de estudo, para compreender como se desenvolve o processo de recuperação da área degradada.

Soma-se a ele o método de análise do conteúdo que usa a técnica de geoprocessamento e sensoriamento remoto, onde possibilitará uma interpretação totalizante da realidade, considerando a importância da recuperação da área para o desenvolvimento socioeconômico da comunidade ali residente, como também para o empreendedor se enquadrar dentro das leis ambientais vigentes em nosso país.

Primeiramente realizou-se um levantamento bibliográfico para compreensão dos conceitos e diretrizes que fundamentam a recuperação de áreas degradadas por exploração de minérios, bem como seus instrumentos. A pesquisa bibliográfica foi formulada a partir de consultas em livros e artigos relacionados à questão de recuperação de áreas e em documentos da própria mineradora.

Em seguida, foi realizada a visita in loco para a coleta de dados, onde foi feita a medição da área do passivo da mina em estudo e a análise quantitativa do rejeito gerado pela mineradora. Os materiais utilizados para coleta e informações no campo foram: Gravador de voz, GPS e câmara fotográfica. Também foram realizadas entrevistas informais com funcionários diretamente envolvidos com o processo de extração do minério.

A análise quantitativa do rejeito foi feita com o uso de GPS, onde foi coletado um ponto geográfico para assim georreferencia-la e depois quantificar o rejeito, também foi feita a análise da área por imagem de satélite.

Já para a área do passivo da mina, foi coletado um ponto geográfico com o GPS e em seguida foi georreferenciada com o uso do SIG - sistema de informações geográficas.

Por fim, foram analisados os resultados obtidos no que tange a recuperação da área degradada e o reaproveitamento do rejeito gerado onde será implantada ao projeto uma melhor forma de alcançar os objetivos gerais. 


\section{Resultados e discussões}

A problemática analisada neste trabalho se resume aos reflexos e/ou problemas ambientais e sociais atribuídos à extração da Vermiculita.

Segundo o art. $1^{\circ}$, da Resolução Conama $\mathrm{n}^{\circ}$ 001/1986 (Brasil, 1986), considera-se impacto ambiental qualquer alteração das propriedades físicas, químicas e biológicas do meio ambiente, causada por qualquer forma de matéria ou energia resultantes das atividades humanas que, direta ou indiretamente, afetam a saúde, a segurança e o bem-estar da população; as atividades sociais e econômicas; a biota; as condições estéticas e sanitárias do meio ambiente; a qualidade dos recursos ambientais.

Assim, os impactos ambientais decorrentes dessa extração iniciam-se na retirada da camada superficial do solo, para a extração do minério, criando as cavas que segundo o PRAD - Plano de Recuperação de Área Degradada da empresa, deveriam ser devidamente recompostas com o estéril gerado pela mineradora, por vários motivos, entre eles a falta de viabilidade financeira ou até de uma fiscalização mais eficaz do órgão ambiental estadual, acontece da mineradora ter essas cavas e não se adequar, não conseguindo reabilitar a área para uso produtivo.

Em visita à área de extração da MPL, observou-se que as cavas são geradas continuamente e bem próximas umas das outras, e por falta de viabilidade econômica, eles não esperam a mina exaurir e já começam a explorar uma nova jazida. Como visto nas Figuras 2 e 3.

Nas Figuras 4 e 5, podemos notar que essas cavas ao longo dos anos tiveram um acréscimo significativo, ocasionando o aumento da área impactada e acarretando em diversos passivos.

Desta forma, foi possível calcular o acréscimo da área e constatar que ao longo dos anos de 2011 a 2013, houve um aumento de $160 \%$ nas áreas de exploração minerária.

Vale salientar, que essas cavas estão inundadas com águas provenientes dos lençóis freáticos (águas subterrâneas), e foi introduzido dentro do ambiente, espécies de peixes. Essa é uma prática muito comum entre as empresas de mineração, porém, este procedimento não está previsto no PRAD da empresa, e para a utilização da piscicultura como forma de recuperação, eles precisariam se adequar junto ao órgão Ambiental.

A MPL possui cavas antigas, geradas na década de 1980, que até hoje não foram devidamente recuperadas formando assim os passivos ambientais em estudo, tendo em vista que a empresa possui as licenças para operar e enquadra-se dentro das leis ambientais vigentes em nosso país.

Dentre essas cavas, foi escolhida uma específica para ser aplicada ao estudo, com a proposta de recuperá-la. A cava escolhida, segundo os próprios funcionários, foi uma das primeiras cavas abertas pela empresa e até hoje encontra-se de forma irregular perante o PRAD, como podemos ver nas imagens a seguir (Figuras 6 e 7).

Utilizou-se a imagen de satélite para georreferenciar a área e fazer uma media da sua área total, em seguida foi calculado o seu volume.

A cava tem aproximadamente $15 \mathrm{~m}$ de profundidade e 2.546,17 $\mathrm{m}^{2}$ de área total, foi exaurida a mais de 30 anos e devido a água de seu interior, o antigo proprietário do terreno preferiu que a área não fosse devidamente recomposta, para poder utilizá-la para alimentar os animais e até mesmo para irrigação. Hoje em dia o terreno pertence à MPL e é de interesse da empresa e que tem por obrigação recuperar a área e se adequar ao seu PRAD.

A forma adequada de recuperar é reaproveitando o rejeito que está depositado no pátio da fábrica de beneficiamento e que acaba se tornando outro passivo.

Consideram-se rejeitos da vermiculita, os materiais que não contem viabilidade econômica, constituídos de solos com altos teores de matérias orgânicos, nutrientes e minerais. A acumulação do rejeito quando feita de forma desordenada, acarreta em significativas alterações topográficas e consequente poluição visual (Leite, 2013).

O concentrado de vermiculita enviado para as unidades de expansão ou esfoliação é classificado em vários tipos diferentes, dependendo da sua granulome 


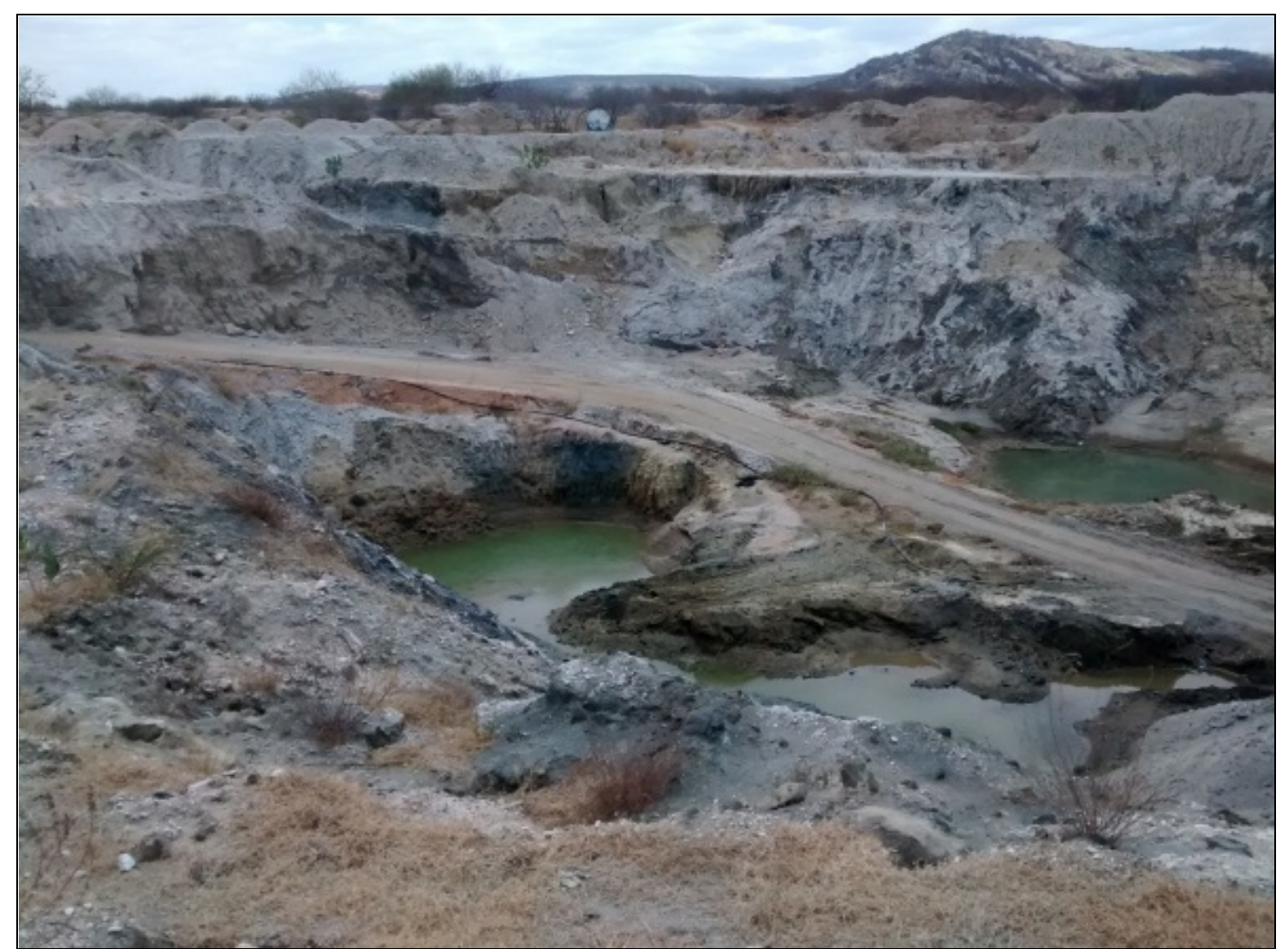

Figura 2. Área de exploração da MPL.

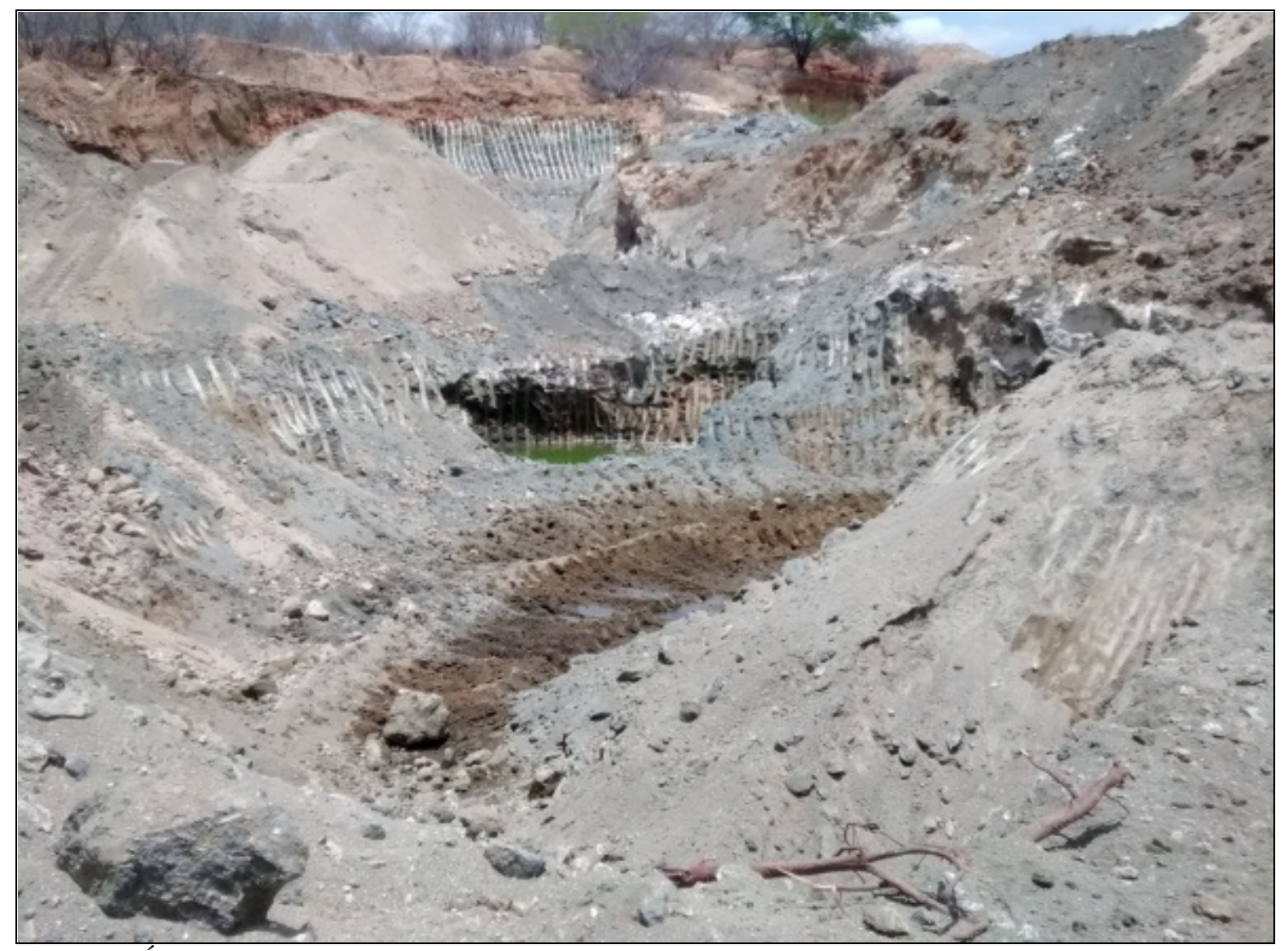

Figura 3. Área de exploração da MPL. 


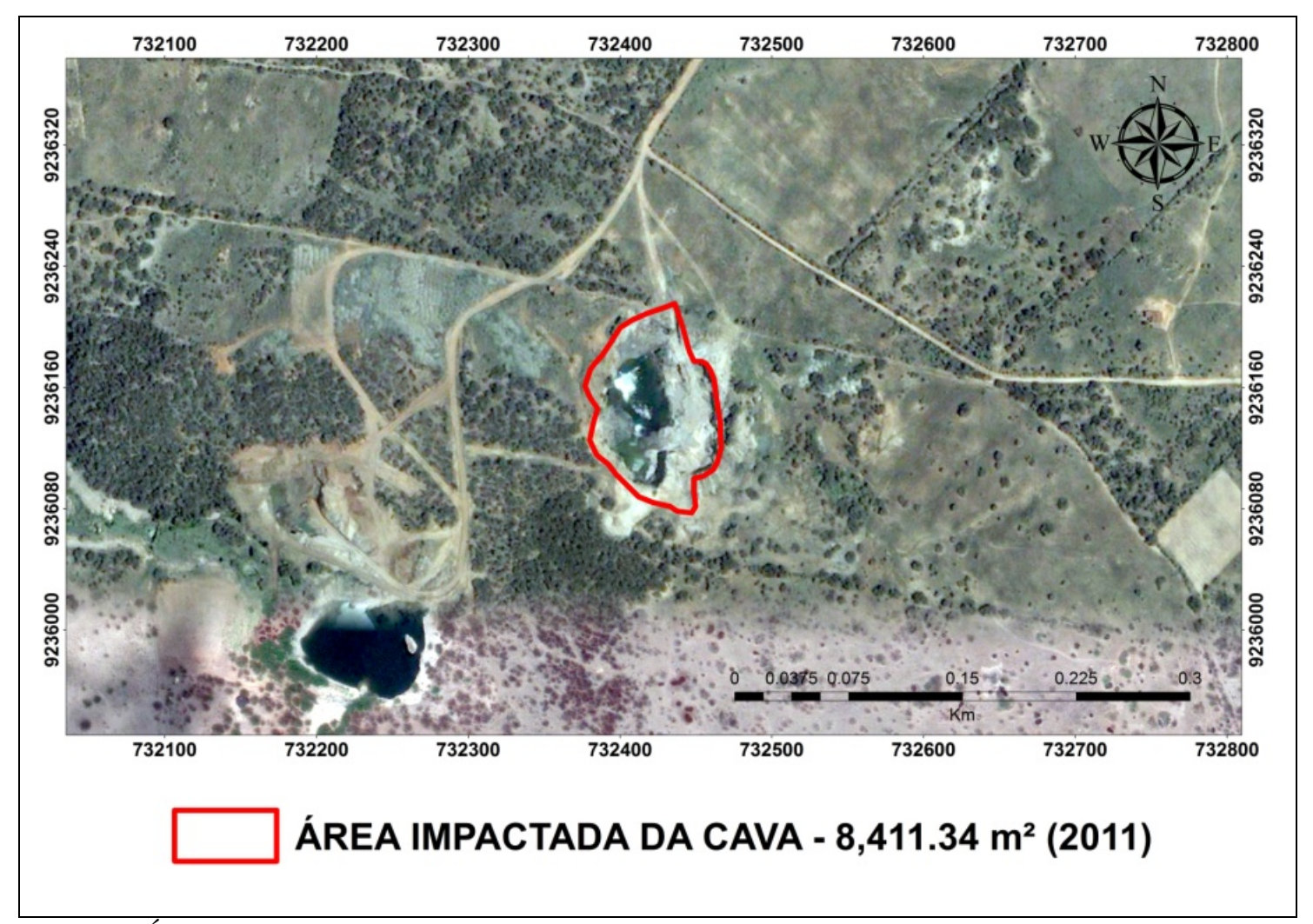

Figura 4. Área Impactada pelas cavas em exploração no ano 2011.

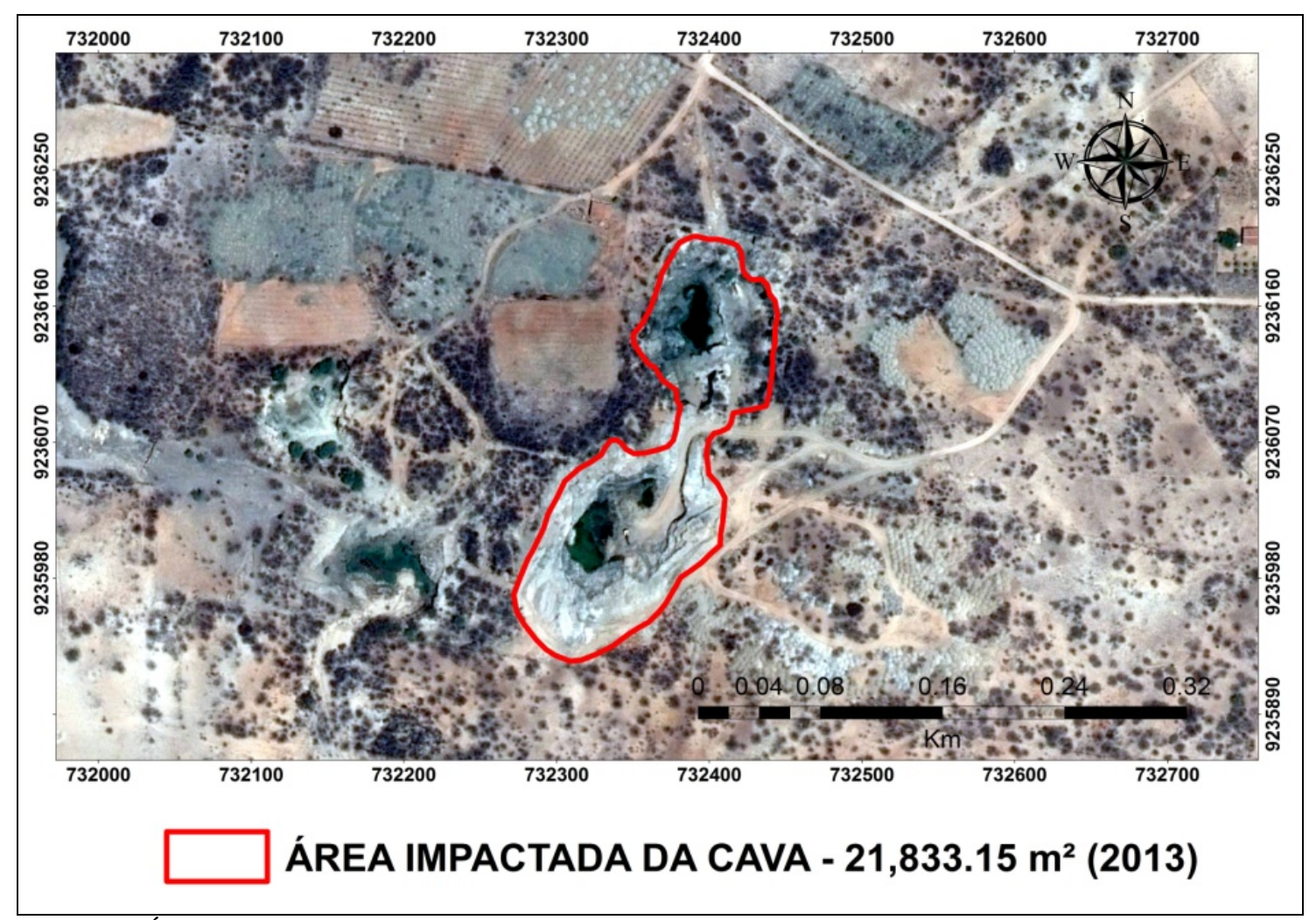

Figura 5. Área impactada pelas cavas em exploração no ano 2013. 


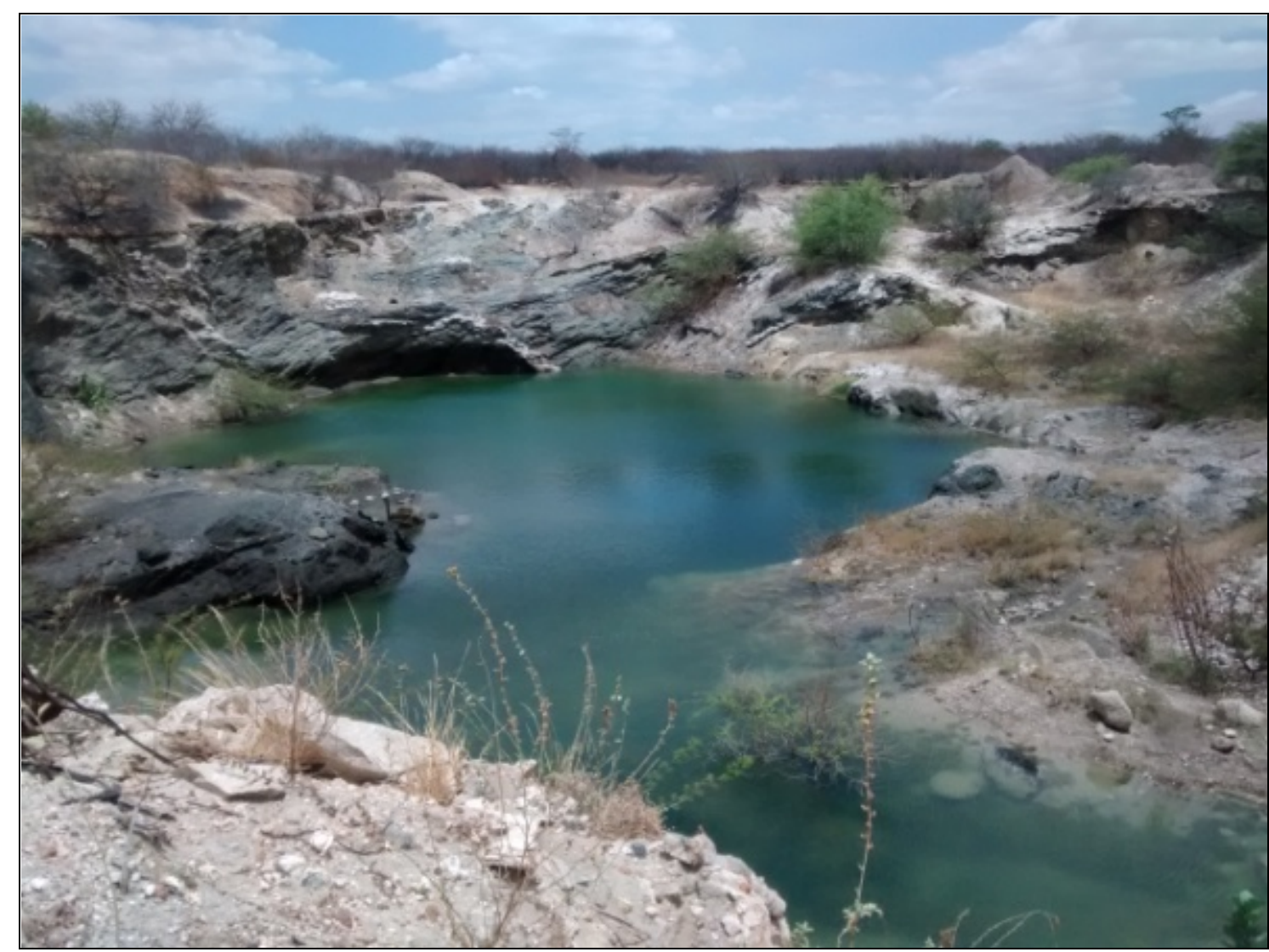

Figura 6. Cava adotada para o estudo.

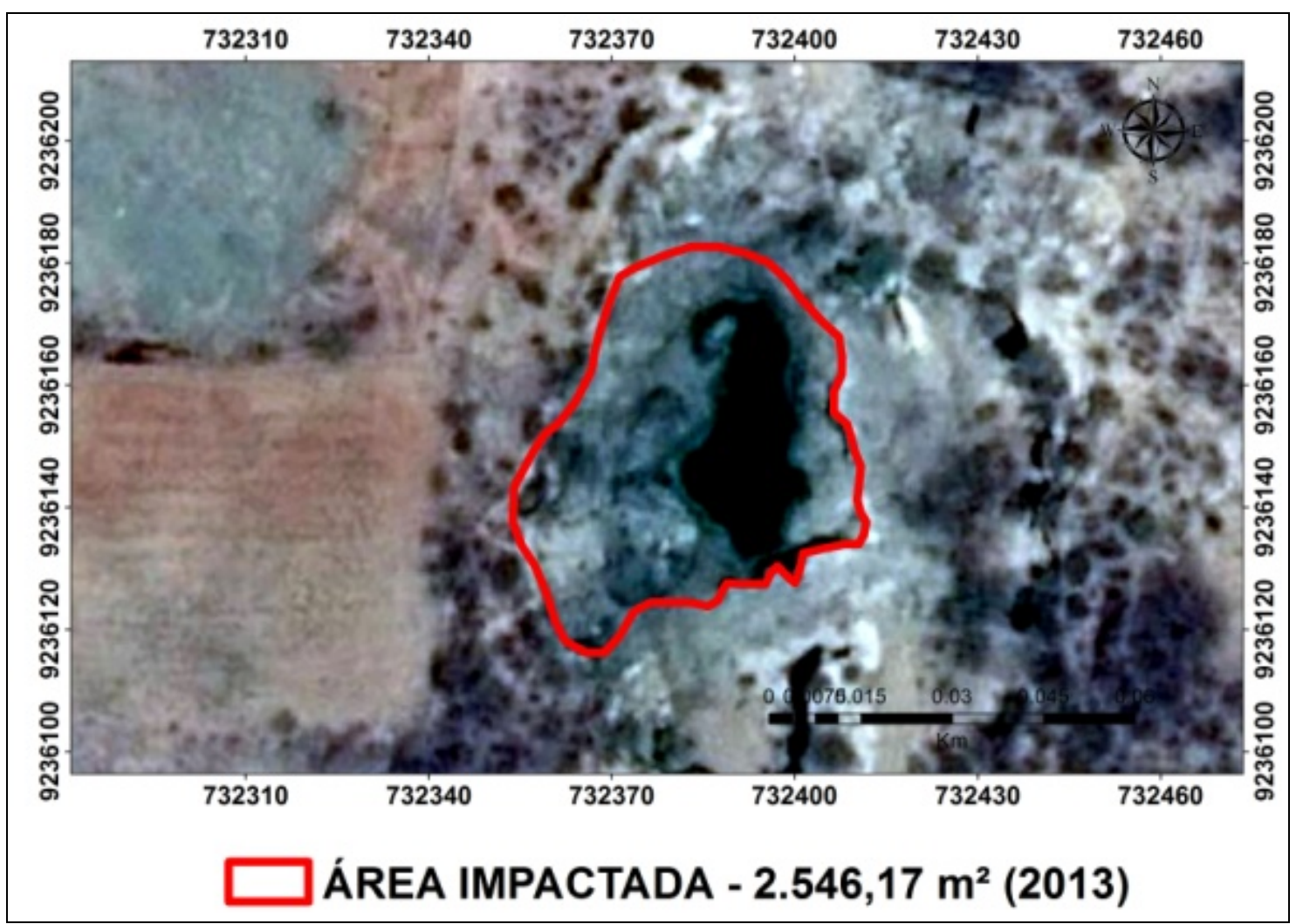

Figura 7. Cava adotada para o estudo. 


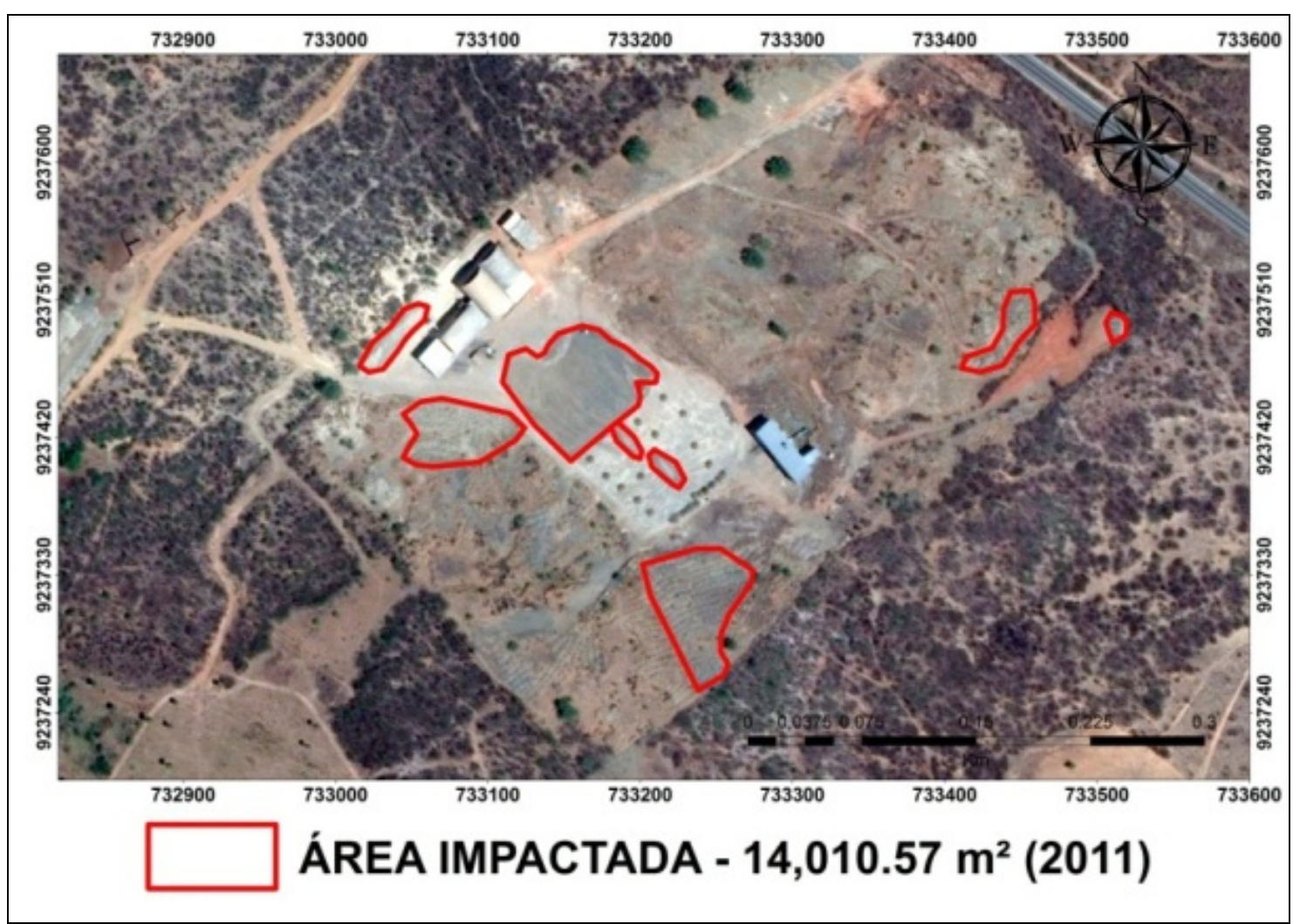

Figura 8. Expansão das áreas impactadas no pátio operacional em 2011.

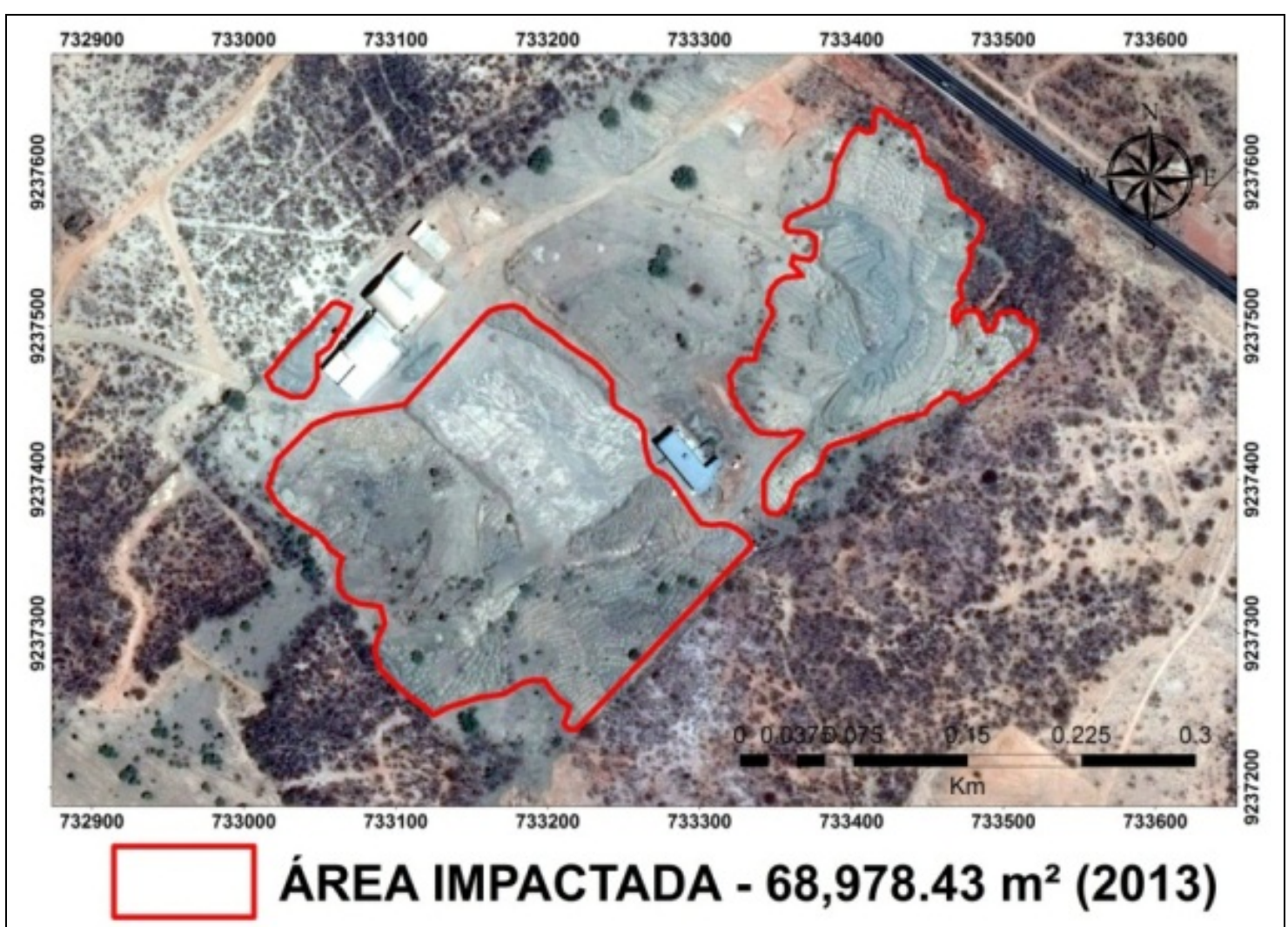

Figura 9. Expansão das áreas impactadas no pátio operacional em 2013. 


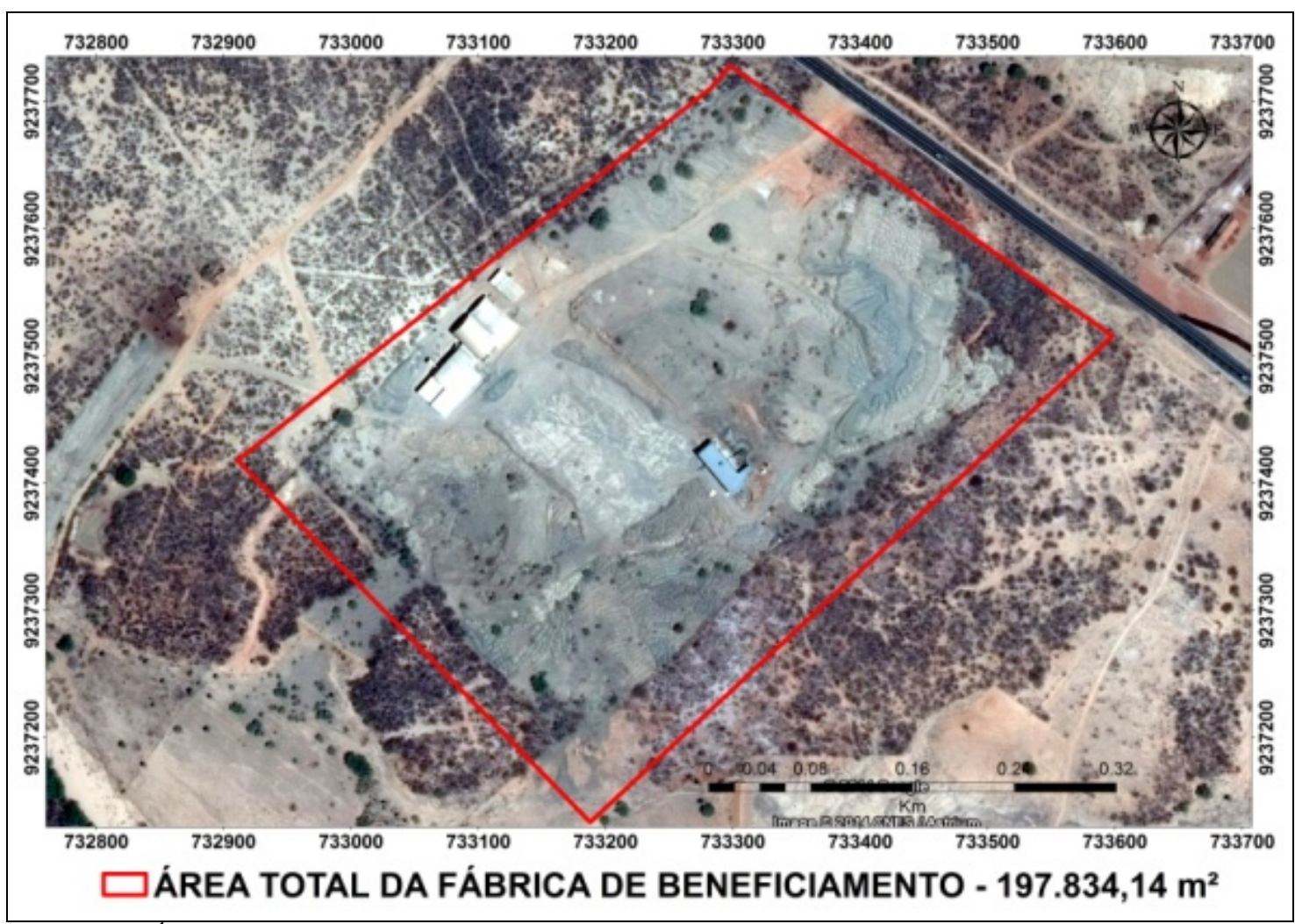

Figura 10. Área total adotada pelo estudo.

tria e pureza. Aquelas com granulometria mais finas são aplicadas na produção de manufaturados para a construção civil, além de serem utilizadas como carreadoras na produção de fertilizantes e de alimentação para animais. As de granulometria mais grossa são utilizadas para fins de horticultura, cultivo e germinação de sementes, dentre outros (Bosco, 2009).

Para a empresa não é de valor econômico extrair a vermiculita de forma micro fina, devido à falta de comércio, sendo então esse material descartado, contendo ainda bastante minério, e ainda podendo ser utilizado como material fertilizante por suas propriedades.

Segundo Veruschka (2010) esse rejeito é muito fértil e propício para geração de mudas, devido a sua capacidade de absorção e de retenção de água.

O rejeito gerado pela MPL é de grande quantidade, a empresa chega a produzir 10 toneladas de minério por dia, desse total 3\% é rejeitado e acumulado de forma incorreta.

De acordo com os dados coletados por imagens de satélite, foi observado que, dentre os anos de 2011 a 2013, houve uma grande alteração na paisagem no que diz respeito ao rejeito depositado de forma inadequada nos pátios e ao redor da fábrica de beneficiamento do minério, como pode ser visto nas Figuras 7 e 8, gerando grandes impactos na área ao redor, como a degradação da vegetação local, irregularidades no relevo, e devido às chuvas acontece o carreamento deste material para o rio próximo, porém, esse procedimento não gera um impacto negativo, e não ocasiona o assoreamento do rio, pois o próprio é intermitente, só enchendo em épocas de chuvas, e por o rejeito ser um material com um alto teor de absorção não traz prejuízos significativos ao rio.

Pode-se observar nas Figuras 8 e 9, a alteração causada e o tamanho da área impactada, onde em 2011 a área era de 14,010.57 $\mathrm{m}^{2}$ e, em 2013, essa área chega a aumentar mais que ao dobro, com $68,978.43 \mathrm{~m}^{2}$.

Desta forma a área impactada teve um acréscimo de $196 \%$ ao ano.

Nas Tabelas 1, 2 e 3, podem-se observar esses valores mais claramente, onde foi calculado o volume do rejeito depositado, e a porcentagem da área que foi impactada. Para chegar a esses resultados, 
Tabela 1. Área impactada no pátio operacional.

\begin{tabular}{c|c|c|c}
\hline Ano & Área $\left.\mathbf{( m}^{\mathbf{2}}\right)$ & Volume $\left.\mathbf{( m}^{\mathbf{2}}\right)$ & Porcentagem (\%) \\
\hline 2011 & $14.010,57$ & $56.042,28$ & $8 \%$ \\
\hline 2013 & $68.978,43$ & $215.913,72$ & $35 \%$ \\
\hline
\end{tabular}

Tabela 2. Área impactada pelas cavas em exploração.

\begin{tabular}{c|r|c}
\hline Ano & Área $\left.\mathbf{( m}^{\mathbf{2}}\right)$ & Volume $\mathbf{( m}^{\mathbf{3}} \mathbf{)}$ \\
\hline 2011 & $8.411,34$ & $126.170,10$ \\
\hline 2013 & $21.833,15$ & $327.497,25$ \\
\hline
\end{tabular}

Tabela 3. Área impactada da cava em estudo.

\begin{tabular}{|c|c}
\hline Área $\left(\mathbf{m}^{\mathbf{2}}\right)$ & Volume $\left.\mathbf{( m}^{\mathbf{2}}\right)$ \\
\hline $2.546,17$ & $38.192,55$ \\
\hline
\end{tabular}

foi adotada uma área total de 197.834,14 $\mathrm{m}^{2}$ onde pode ser observado na Figura 10 e para a área de deposito do rejeito, adotou-se uma média, de $4 \mathrm{~m}$ de altura.

Já para o cálculo de volume da cava, adotou-se uma média de $15 \mathrm{~m}$.

Portanto, de acordo com os dados apresentados, verificou que a quantidade de rejeito é suficiente para preencher a cava, e essa alternativa torna-se viável devido a grande quantidade do rejeito e da proximidade entre a mina e a fábrica de beneficiamento, podendo posteriormente dar o uso que desejarem a esses ares, já que o solo reposto é bastante fértil e com a implantação de vegetação introduzida, pode-se adaptar muito bem ao ambiente, trazendo assim benefícios para a população local e para a empresa.

\section{Conclusões}

1. De 2011 a 2013 houve um aumento significativo de 160 \% na área de exploração.

2. De 2011 a 2013 houve um aumento de $392 \%$ de rejeito depositado na área do pátio operacional.

3. A quantidade de rejeito é suficiente para preencher a cava existente.

4. De forma concisa, conclui-se que a mineração é uma atividade econômica imprescindível ao desenvolvimento da sociedade, todavia seus efeitos e consequências devem ser analisados de forma minuciosa e ressalvando o bem estar socioambiental.

5. Nesta perspectiva, devem-se propor mecanismos práticos que possibilitem a mitigação dos impactos negativos da mineração, visando um desenvolvimento socialmente justo e ambientalmente correto.

\section{Agradecimentos}

Agradecemos à empresa MPL Mineração Pedra Lavrada pelas facilidades concedidas para a realização desse estudo.

\section{Declaração de conflito de interesses}

Os autores declaram não haver conflitos de interesses.

\section{Referências}

Bosco, J. B. C. PCA/RCA/PRAD - Mineração Pedra Lavrada - Paraíba. Santa Luzia: MPL, 2009.

Brasil. Leis, decretos, etc. Decreto $\mathbf{n}^{\mathbf{0}}$ 97.632, de 10 de abril de 1989. Dispõe sobre a regulamentação do artigo $2^{\circ}$, inciso VIII, da Lei $n^{\circ}$ 6.938, de 31 de agosto de 1981, e dá outras providências. Disponível em: $<$ http://www.planalto.gov.br/ccivil_03/decreto/1 980-1989/D97632.htm>. Acesso em: 20 maio 2014.

Brasil. Leis, decretos, etc. Constituição da República Federativa do Brasil. Disponível em: <http://www.planalto.gov.br/ccivil_03/ constituicao/ConstituicaoCompilado.htm>.

Acesso em: 20 maio 2014. 
Brasil. Leis, decretos, etc. Lei $\mathbf{n}^{0}$ 6.938, de 31 de agosto de 1981. Dispõe sobre a Política Nacional do Meio Ambiente, seus fins e mecanismos de formulação e aplicação, e dá outras providências. Disponível em: <http://www.planalto.gov.br/ccivil_03/leis/L693 8compilada.htm>. Acesso em: 20 maio 2014.

Brasil. Leis, decretos, etc. Lei $\mathbf{n}^{0}$ 7.805, de 18 de julho de 1989. Altera o Decreto-Lei $n^{\circ} 227$, de 28 de fevereiro de 1967, cria o regime de permissão de lavra garimpeira, extingue o regime de matrícula, e dá outras providências. $<$ http://www.planalto.gov.br/ccivil_03/Leis/L78 05.htm>. Acesso em: 20 maio 2014.

Brasil. Leis, decretos, etc. Resolução CONAMA n ${ }^{\circ}$ 001, de 23 de janeiro de 1986. Disponível em: <http://www.mma.gov.br/port/conama/legiabre. cfm?codlegi=23>. Acesso em: 23 out. 2014.

CPRM - Serviço Geológico do Brasil. Disponível em: $<$ http://www.ibge.gov.br/home/>. Acesso em: 23 out. 2014.

DNPM - Departamento Nacional de Produção Mineral - Brasil. Disponível em: $<$ http://www.dnpm.gov.br>. Acesso em: 20 maio 2014.

EMBRAPA - Empresa Brasileira de Pesquisa Agropecuária. Curso de recuperação de áreas degradadas. A visão da ciência do solo no contexto do diagnóstico, manejo, indicadores de monitoramento e estratégias de recuperação. Rio de Janeiro: Embrapa Solos, 2008.

Foschini, R. C.; Ribeiro, C. A. G.; Salvador, N. N. B. Legislação ambiental sobre recuperação de áreas degradadas pela exploração de minérios e o uso do mecanismo da caução. Anais do IV Congresso de Meio Ambiente da AUGM, São Carlos, 2009. Disponível em: $<$ http://www.ambiente-augm.ufscar.br/uploads/ A2-152.pdf>. Acesso em: 23 out. 2014.
Gripp, M. F. A.; Nonato, C. A. A preservação e recuperação do meio ambiente no planejamento e projeto de lavra. II Congresso Ítalo Brasileiro de Engenharia de Minas. São Paulo, 1993.

IBGE - Instituto Brasileiro de Geografia e Estatística. Disponível em: <http://www.ibge.gov.br/home/>. Acesso em: 23 out. 2014.

Kageyama, P. Y.; Gandara, F. B.; Oliveira, R. G. Biodiversidade e Restauração da floresta tropical. In: Kageyama, P. Y.; Oliveira, R. E.; Moraes, L. F. D.; Engel, V. L.; Gandara, F. B. (Org.). Restauração ecológica de ecossistemas naturais. Botucatu: FEPAF, 2003. p. 27-48.

Leite, A. A. PCA/RCA/PRAD - Mineração Pedra Lavrada - Paraíba. Santa Luzia: MPL, 2013.

Silva, J.P. S. Impactos Ambientais causados por mineração. Revista Espaço da Sophia, v. 1. n. 8, 13 p., 2007. Disponível em: $<$ http://www.registro.unesp.br/sites/museu/base dedados/arquivos/00000429.pdf>. Acesso em: 23 out. 2014.

Taveira, A. L. S. Provisão de recursos financeiros para o fechamento em empreendimentos minerários. São Paulo: Escola Politécnica/USP, 2003. (Tese de doutorado em Engenharia Mineral).

Veruschka, E. A. T. Rejeitos de mineradoras como substrato na produção de mudas de pinhão manso. Campina Grande: Universidade Federal de Campina Grande, 2010.

Warhursh, A.; Noronha, L. Integrated environmental managenent through planning for closure front he outset the clallenges. Environmental policy un mining: corporate strategy and planning for closure. United State of America: Lewis Publishers, 1999. p. 13-32.

Informação da Licença: Este é um artigo Open Access distribuído sob os termos da Licença Creative Commons Attribution, que permite uso irrestrito, distribuição e reprodução em qualquer meio, desde que a obra original seja devidamente citada. 
